\section{Management of Ischemic Stroke during cardiac catheterization: A case report and review of literature}

\author{
Naoufal Chouaib*, Said Jidane, Mounir Lekhlit, Ahmed Belkouch, \\ Tahir Nebhani, Saad Zidouh and Lahcen Belyamani
}

Department of Emergency, Military Training Hospital Mohamed V, Faculty of Medicine and Pharmacy, University Mohamedd V, Rabat, Morocco

\section{Introduction}

Stroke following coronary interventions is a devastating and most dreaded complication with significant morbidity and mortality. Various factors have been ascribed for this complication including the technical errors [1]. A small percentage of strokes are iatrogenic, including those associated with invasive cardiac procedures. According to the literature, it is a rare complication of left heart catheterization [2]. Percutaneous coronary intervention is increasingly used to treat patients with diffuse atherosclerosis, acute coronary syndromes and even high-risk patients such as low ejection fraction [1]. The authors describe a patient who underwent percutaneous coronary intervention in the context of inferior infarction, which was complicated by ischemic stroke during cardic catheterization.

\section{Patient and Observation}

A 60-year-old man, with a personal history of dyslipidemia, was admitted to hospital's emergency room with chest pain squeezing type, continuous, radiating to left shoulder. On admission, his pulse was $120 \mathrm{bpm}$, BP was 94/66mmHg. Rest of general examination was normal, and the admission electrodardiogram (ECG) revealed sinus rhythm with ST elevation in anterior segment. A brief echocardiogram showed no left ventricular hypertrophy, preserved global systolic function, and akinesia of septal wall and akinesia in apex and adjacent segments. We decided to perform urgent cardiac catheterization. Angioplasty showed acute occlusion of more than $20 \mathrm{~mm}$ along the average anterior interventricular artery with the presence of an intraluminal thrombus at this level and absence of antegrade flow. The establishment of two stents at this artery was successful and resumed downstream revascularization. Immediate neurologic consultation showed that the patient was awake but aphasic, with poor verbal expression. Moderate

\section{More Information}

*Address for Correspondence: Chouaib Naoufal, Department of Emergency, Military Training Hospital Mohamed V, Faculty of Medicine and Pharmacy, University Mohamedd V, Rabat, Morocco, Tel: 00212661321415; Email: naoufal_chouaib@hotmail.com

Submitted: 08 July 2019

Approved: 21 August 2019 Published: 22 August 2019

How to cite this article: Chouaib N, Jidane S, Lekhlit M, Belkouch A, Nebhani T, et al. Management of Ischemic Stroke during cardiac catheterization: A case report and review of literature. J Clin Intensive Care Med. 2019; 4: 040-041.

DOI: dx.doi.org/10.29328/journal.jcicm.1001024

Copyright: Chouaib N, et al. This is an open access article distributed under the Creative Commons Attribution License, which permits unrestricted use, distribution, and reproduction in any medium, provided the original work is properly cited

Check for updates right hemiparesis was observed. The National Institutes of Health Stroke Scale (NIHSS) score was 3. An urgent cranial computed tomography (CT) scan was performed immediately due to suspicion of cerebral infarction. CT showed neither intracranial hemorrhage nor obvious parenchymal hypodensity, but spontaneous hyperdensity suggestive of occlusion of the right middle cerebral artery was observed, thus confirming the diagnosis of ischemic stroke. The decision not to thrombolyse was made. A repeat cranial CT scan 24 hours after confirmed a left temporal infarction. The NIHSS score was two days after. The patient was discharged after five days.

\section{Discussion}

Neurologic complications are infrequently associated with diagnostic cardiac catheterization, but may be devastating to the patient and the family. The reported frequency of clinically apparent stroke ranges from $0.03 \%$ to $0.38 \%$ [3-5], while the reported frequency of silent stroke may be much higher, up to $15.5 \%$ The recent shift to more frequent catheterization of older patients with severe coronary disease has led to the need for more emphasis on the determination of risk factors for catheterization-associated cerebral infarction, as well as its prevention, rapid diagnosis and treatment.

Blumer was amongst the first to extensively discuss the importance of embolism as a complication of cardiac 
infarction. He stated that mural thrombi are common following cardiac infarction, and that fragments may detach and produce embolic phenomena [1]. Strokes among patients with acute coronary syndromes enrolled in the Organization to Assess Strategies for Ischemic Syndromes (OASIS) I and II studies were associated with six-month mortality rates of $27 \%$ [6]. Routinely used thrombolytic agents and anticoagulants are associated with the cholesterol embolization syndrome [7]. Dukkipati, et al. found that cerebrovascular events were more common in patients with pre-existing hypertension, diabetes, and renal insufficiency [8]. Approximately one-third of all strokes occur within 24 hours following admission, whereas about two-thirds occur in the first week after the myocardial infarction [1]. Thrombolysis has been established as an effective treatment for acute ischemic stroke, but its benefit and risk for ischemic strokes specifically in the cardiac catheterization setting have not previously been investigated. Bleeding risks of thrombolysis might be increased after cardiac catheterization, owing to the recent invasive procedure and the concurrent administration of antithrombotic medications [9].

Antithrombotic medications administered during the cardiac catheterization procedure might influence the decision to treat with thrombolytics. Heparin, if associated with a prolonged a PTT, is a contraindication for intravenous rt-PA in the standard protocol [10]. However, heparin is routinely administered in intra-arterial thrombolysis cases. Therefore, intra-arterial rt-PA or mechanical revascularization might be a consideration in this situation, depending on the dose and timing of heparin received [9].

\section{Conclusion}

This case describes a rare complication who underwent percutaneous coronary intervention in the context of inferior infarction, which was complicated by ischemic stroke and discuss the problem of use thrombolic agents and anticoagulants.

\section{References}

1. Sanket KM, Anand BS. Ischaemic Stroke Following Percutaneous Transluminal Coronary Angioplasty (PTCA): A Rare Complication Cardiology. J Clin Diagnostic Res. 2014; 8: 1-2.

2. Magno $P$, Loureiro J, Marques A, Abreu PF, Candido M, et al. AVC isquémico pericateterismo cardíaco: a propósito de um caso clínico. Rev Port Cardiol. 2007; 26: 1033-1040.

3. Fuchs S, Stablile E, Kinnaird TD, Mintz GS, Gruberg L, et al. Stroke complicating percutaneous coronary interventions: incidence, predictors, and prognostic implications. Circulation. 2000; 106: 86-96. PubMed: https://www.ncbi.nlm.nih.gov/pubmed/12093775

4. Segal AZ, Abernethy MW, Palacios IF, BeLue R, Rordorf G. Stroke as a complication of cardiac catheterization: risk factors and clinical features. Neurology. 2001; 56: 975-977.

PubMed: https://www.ncbi.nlm.nih.gov/pubmed/11294941

5. Leker RR, Pollak A, Abramsky O, Ben-Hur T. Abundance of left hemispheric embolic strokes complicating coronary angiography and PTCA. J Neurol Neurosurg Psychiatry. 1999; 66: 116-119. PubMed: https://www.ncbi.nlm.nih.gov/pubmed/9886472

6. Cronin L, Mehta SR, Zhao F, Pogue J, Budaj A, et al. Stroke in relation to cardiac procedures in patients with non-ST-elevation acute coronary syndrome: a study involving $>18,000$ patients. Circulation $2001 ; 104$ : 269-276.

PubMed: https://www.ncbi.nlm.nih.gov/pubmed/11457743

7. Pettolot G, Bracco J, Barrillon D, Baudouy M, Morand P. Cholesterol embolization. Unrecognized complication of thrombolysis. Circulation. 1998; 97: 15-22

PubMed: https://www.ncbi.nlm.nih.gov/pubmed/9576434

8. Dukkipati S, O'Neill WW, Harjai KJ. Characteristics of cerebrovascular accidents after percutaneous coronary interventions. J Am Coll Cardiol. 2004; 43: 1161-1167.

PubMed: https://www.ncbi.nlm.nih.gov/pubmed/15063423

9. Khatri P, Robert A, Taylor, MD. The Safety and Efficacy of Thrombolysis for Strokes after Cardiac Catheterization. J Am Coll Cardiol. 2008; 51: 906-911.

PubMed: https://www.ncbi.nlm.nih.gov/pubmed/18308158

10. NINDS rt-PA Stroke Study Group. Tissue plasminogen activator for acute ischemic stroke. N Engl J Med. 1995; 333: 1581-1587. 